\title{
Low Frequency Magnetic Fields and Safety
}

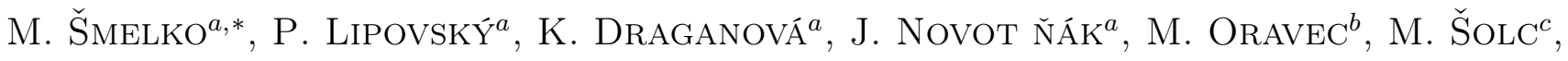 \\ R. Andoga ${ }^{a}$ And R. RozenberG ${ }^{a}$ \\ ${ }^{a}$ Technical University of Košice, Faculty of Aeronautics, Rampová 7, 04121 Košice, Slovak Republic \\ ${ }^{b}$ Technical University of Košice, Faculty of Mechanical Engineering, Letná 9, 04200 Košice, Slovak Republic \\ ${ }^{c}$ Technical University of Košice, Faculty of Materials, Metallurgy and Recycling, \\ Letná 9, 04200 Košice, Slovak Republic
}

\begin{abstract}
Magnetic fields in the environment can have the natural or technical origin. Their impact on the human organism was confirmed by the multiple scientific studies. The standards for living of people in the places with the increased intensity of magnetic fields can have the influence on the psychical performance of them, or the chemical reactions running in the organism. There are studies referring the impact of the low frequency magnetic field on the human organism and processes in it. While exploring the magnetic field radiation of some artificial sources, we found that the main part of the magnetic field induced into the organism is the field generated by the movements of the organism in a non-homogeneous magnetic field. Most of the standard studies do not take this field into account. The measurements of the low frequency magnetic fields induced to human body by the movement in the Earth magnetic field are presented in the article, as well as the measurements of artificial sources of magnetic field. The measured values are confronted with the valid health and safety standards and the article points to the dissonance between the standards and the induced magnetic fields.
\end{abstract}

DOI: 10.12693/APhysPolA.137.693

PACS/topics: work safety, magnetic field, low frequency

\section{Introduction}

Biological material exists for several millions years in the Earth magnetic field. Humans have been adapting to this environment for thousands of years. The InTech devices (artificial manmade technical devices) exist less than 200 years and produce the artificial local magnetic fields, stronger than the Earth magnetic fields, which are hard for humans to adapt with.

Standards for limiting values of magnetic field for employees and for the population have been recorded only since 1995 [1]. Current state of the standards for the low frequency magnetic fields does not respect the current knowledge of the field. The disproportions among the standards are noticeable. The first group is created by the ICNIRP recommendations [2-4] and its derivates are as per national law standards. The second group of standards is created by the standards for the hygiene of the buildings [5]. The third group is presented by the opinion of the doctors [6] that present their own points of view. The unknown causality of the impact of sources of low magnetic field on the near environment and on the humans, cause the disproportions between the limiting values [1-6]. The movement of the opinions to the limiting values over the years is presented in Table I.

In the 2014 the ICNIRP issued [7], which took into account the rate of change of the magnetic induction $\mathrm{d} B / \mathrm{d} t$. In the field of the building of hygiene for low

*corresponding author; e-mail: miroslav.smelko@tuke.sk frequency magnetic fields the SBM-2008 standard is recommended [5], which specifies the limiting values of the magnetic field for the alternating fields in four categories below $20 \mathrm{nT}$, below $100 \mathrm{nT}$, below $500 \mathrm{nT}$ and over $500 \mathrm{nT}$, for at least four hours of exposition to the magnetic field. The EUROPAEM 2016 [6] standard for low frequency fields (frequencies over $3 \mathrm{~Hz}$ ) for prevention, diagnostic, and healing of medical problems, associated with electromagnetic fields specifies the limiting values as $1000 \mathrm{nT}$ for day and night and $300 \mathrm{nT}$ for sensitive people.

\section{Impact of low frequency magnetic fields on human}

The important informations from the studies gathered in [8] and presented in Table II show the impact of the magnetic low frequency field sources (MLFFS) on the organism and its biochemistry.

\section{Measurements and results}

The measurements presented in the article were performed by the magnetometer VEMA-04 [9]. The device is designed for the vector measurements and the oscilloscopic representations of the stationary and lowfrequency magnetic field. The device is capable for measuring and recording sets of time and spatial measurements, as well as analysis in the time, frequency, and spatial area. The resolution of magnetometer is below $2 \mathrm{nT}$ in the frequency range from $0 \mathrm{~Hz}$ to $250 \mathrm{~Hz}$ and the measuring range is $\pm 80000 \mathrm{nT}$. 
The movement of limiting values in the ICNIRP recommendations and its derivate [1-3].

TABLE I

\begin{tabular}{|c|c|c|c|c|c|}
\hline \multicolumn{6}{|c|}{ ENV 50166/1995, Human exposure to electromagnetic fields low-frequency, 1995 [1] } \\
\hline employer & \multirow{2}{*}{\multicolumn{5}{|c|}{$\begin{array}{l}2 \times 10^{-3} \mathrm{~T} \text { at } 50 \mathrm{~Hz} \\
5 \times 10^{-4} \mathrm{~T} \text { at } 50 \mathrm{~Hz}\end{array}$}} \\
\hline population & & & & & \\
\hline \multicolumn{6}{|c|}{$\begin{array}{l}\text { ICNIRP Guidelines for limiting exposure to time-varying electric, magnetic and electromagnetic fields } \\
\text { (up to } 300 \mathrm{GHz}), 1998[2] \text { (Note: } B[\mu \mathrm{T}], f[\mathrm{kHz}] \text { ) }\end{array}$} \\
\hline range & under $1 \mathrm{~Hz}$ & $1-8 \mathrm{~Hz}$ & $8-25 \mathrm{~Hz}$ & $0.25-0.82 \mathrm{kHz}$ & $0.82-65 \mathrm{kHz}$ \\
\hline employer & $2 \times 10^{5}$ & $2 \times 10 / f^{2}$ & $2.5 \times 10^{4} / f$ & $25 / \mathrm{f}$ & 307 \\
\hline population & $4 \times 10^{4}$ & $4 \times 10^{4} / f^{2}$ & $5000 / f$ & $5 / f$ & 625 \\
\hline
\end{tabular}

ICNIRP Guidelines for limiting exposure to time-varying electric and magnetic fields $(1 \mathrm{~Hz}-100 \mathrm{kHz}), 2010$ [3] (Note: $B[\mathrm{~T}], f[\mathrm{~Hz}])$

\begin{tabular}{l|c|c|c|c|c}
\hline range & $1-8 \mathrm{~Hz}$ & $8-25 \mathrm{~Hz}$ & $25-300 \mathrm{~Hz}$ & $300 \mathrm{~Hz}-3 \mathrm{kHz}$ & $3 \mathrm{kHz}-10 \mathrm{MHz}$ \\
\hline employer & $0.2 / f^{2}$ & $2.5 \times 10^{-2} / f$ & 0.001 & $0.3 / f$ & 0.0001 \\
population & $4 \times 10^{-2} / f^{2}$ & $5 \times 10^{-3} / f$ & $2 \times 10^{-4}$ & $8 \times 10^{-2} / f$ & 0.000027
\end{tabular}

Impact of MLFFS on the organism and biochemistry [8].

TABLE II

\begin{tabular}{c|l|cc}
\hline \hline Group & \multicolumn{1}{|c|}{ Effect } & $B[\mu \mathrm{T}]$ & $f[\mathrm{~Hz}]$ \\
\hline \multirow{2}{*}{ cell structures } & isolated cells & 1000 & $0-100$ \\
& nerves stimulation & $15-25$ & 1 \\
\hline \multirow{5}{*}{ functions } & recognition & $20.0-1260$ & 50 \\
& decreased accuracy of numerical task & 600 & 50 \\
& CNS without contradictory changes of behaviour & 3000 & 50 \\
& cardiovascular system, increase of hearth arrhythmia & 20 & 60 \\
& immunity system, increase of oxidation reaction of monocytes & 2000 & $50-600$ \\
& reproduction (rodents) without changes & 3000 & 50 \\
& CNS changes of opioid hippocampus receptors, norepinephrine & 100 & 50 \\
& disruption of DNA sequence during 24 and 72 h exposition & 1000 & 50 \\
\hline
\end{tabular}

CNS - central nervous system

The measurements were performed to supplement the knowledge, causality, and remit to possible approaches on investigations of human responses to low frequency magnetic fields. The stable and mobile sources of magnetic field were monitored and the total value of the vector was measured. The measurements results are summarized, and compared to the same sources measured in 1999 in Table III.

We have measured several technical devices with the potential of the emission of magnetic field during the years 2016 and 2017 [8] as well. As an example we present the arc welding [10] where the induction of the magnetic field in the distance of $0.4 \mathrm{~m}$ from the head of the welder was in range from the $5.0 \times 10^{-6} \mathrm{~T}$ at $5 \mathrm{~Hz}$ through $1.0 \times 10^{-5} \mathrm{~T}$ at $50 \mathrm{~Hz}$ up to $0.6 \times 10^{-6} \mathrm{~T}$ at $100 \mathrm{~Hz}$. The measurements on the mobile sources (car, electric car, train, and elevator) were performed consequently for the purpose of the comparison of the induced magnetic fields to the human body caused by body movement in Earth magnetic field.

The experiment shown in Fig. 1 was performed in ordinary magnetic environment during the feast days by Suzuki SX4 car. Several intervals are presented during the record of magnetic induction in $x, y$, and $z$ axis $\left(B_{x}, B_{y}, B_{z}\right)$ and its resulting vector of magnetic
TABLE III

Comparison of the intensity of the magnetic field generated by home $50 \mathrm{~Hz}$ sources [8].

\begin{tabular}{l|c|c|c|c}
\hline \hline \multirow{2}{*}{\multicolumn{1}{c}{ Source }} & \multicolumn{4}{|c}{$B[\mathrm{~T}]$ in distance } \\
\cline { 2 - 5 } & \multicolumn{2}{|c|}{ Year 1999} & Year $2015-2017$ \\
\cline { 2 - 5 } & $3 \mathrm{~cm}$ & $30 \mathrm{~cm}$ & $3 \mathrm{~cm}$ & $30 \mathrm{~cm}$ \\
\hline shaving machine & $1.5 \times 10^{-3}$ & $9.0 \times 10^{-6}$ & $7.8 \times 10^{-4}$ & $4.0 \times 10^{-6}$ \\
vacuum cleaner & $8.0 \times 10^{-4}$ & $2.0 \times 10^{-5}$ & $2 \times 10^{-5}$ & $1.5 \times 10^{-6}$ \\
microwave oven & $2.0 \times 10^{-4}$ & $8.0 \times 10^{-6}$ & $2.8 \times 10^{-5}$ & $1.4 \times 10^{-6}$ \\
transistor radio & $5.6 \times 10^{-5}$ & $1.0 \times 10^{-6}$ & $1.2 \times 10^{-7}$ & $4.8 \times 10^{-8}$ \\
electric oven & $5.0 \times 10^{-5}$ & $5.0 \times 10^{-7}$ & $2.4 \times 10^{-6}$ & $3.2 \times 10^{-7}$ \\
electric iron & $3.0 \times 10^{-5}$ & $3.0 \times 10^{-7}$ & $8.2 \times 10^{-7}$ & $1.4 \times 10^{-7}$ \\
refrigerator & $1.7 \times 10^{-6}$ & $2.5 \times 10^{-7}$ & $5.5 \times 10^{-9}$ & $3.5 \times 10^{-9}$
\end{tabular}

induction $\left(B_{\text {Total }}\right)$. The $x$ axis was aligned with the Front-Rear car axis, the $y$ axis was aligned with the LeftRight car axis, and the $z$ axis was aligned with TopBottom axis. The magnetometer was placed under the car rear window in the middle of the seat at the height of the passenger head.

The car was standing with engine running before the 7th second of the record. At this interval the background magnetic field in range of $\mu \mathrm{T}$ can be seen. We refer the values up to $20 \mu \mathrm{T}$ as magnetically clean environment, 
TABLE IV

The monitored processes and changes of magnetic induction during these processes.

\begin{tabular}{c|c|c|c|c|c|c|c}
\hline \hline Device & $\begin{array}{c}\mathrm{d} B_{x} / \mathrm{d} t \\
{\left[\mu \mathrm{T} \mathrm{s}^{-1}\right]}\end{array}$ & $\begin{array}{c}\mathrm{d} B_{y} / \mathrm{d} t \\
{\left[\mu \mathrm{T} \mathrm{s}^{-1}\right]}\end{array}$ & $\begin{array}{c}\mathrm{d} B_{z} / \mathrm{d} t \\
{\left[\mu \mathrm{T} \mathrm{s}^{-1}\right]}\end{array}$ & $\begin{array}{c}\mathrm{d} B_{\text {total }} / \mathrm{d} t \\
{\left[\mu \mathrm{T} \mathrm{s}^{-1}\right]}\end{array}$ & $\begin{array}{c}\text { Change } \\
\text { duration }[\mathrm{s}]\end{array}$ & $\begin{array}{c}\text { Process } \\
\text { period }[\mathrm{s}]\end{array}$ & Process \\
\hline \multirow{3}{*}{ train } & 8876 & 149 & 2711 & 7650 & 0.131 & 23 & acceleration \\
& 14161 & 168 & 2747 & 1215 & 0.15 & 23 & deceleration \\
& 696 & 0.36 & 385 & 630 & 52 & 52 & entering tunnel \\
leaving tunnel \\
\hline elevator - & 1265 & 1265 & 662 & 1294 & 215 & 215 & entering elevator \\
15 floors & 0.39 & 1029 & 940 & 1443 & 141 & & leaving elevator \\
\hline \multirow{2}{*}{ car } & 0.14 & 0.14 & 519 & 660 & 16 & 367 & drive in circle \\
& 1028 & 113 & 0.10 & 247 & 28 & & $90^{\circ}$ turn
\end{tabular}

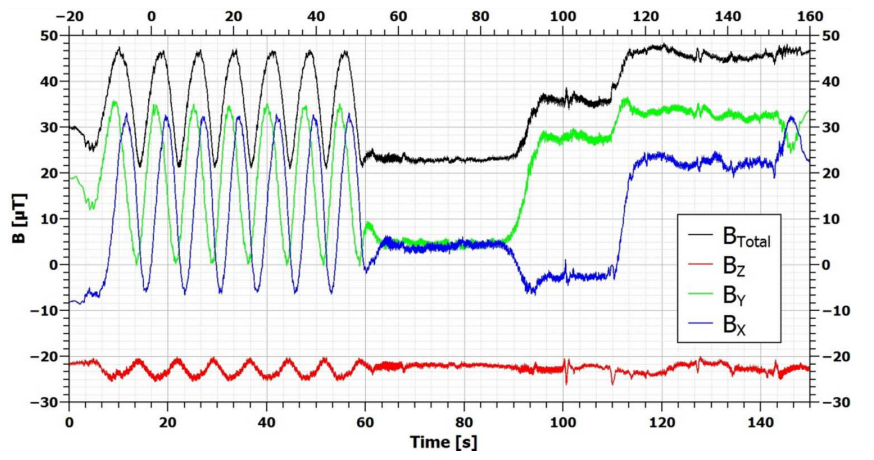

Fig. 1. The changes of magnetic field in vehicle during the driving to the circles and by the reference track.

while in ordinary conditions the values are much higher. Between the 7 th and 60th second the car was moving in the circles as small as possible. After 60th second the car was moving along the reference track, created by the three straight stretch of the road, separated by the two 90 degree turns. This measurement was supplement by few different processed, as shown in Table IV. These processes can represent the inputs for risk measurement tool [11].

\section{Discussions}

All ICNIRP recommendations come from the vector basis of the magnetic field even though this is not considered in the limiting values. It can be clearly seen from the realized experiments (Table III and Table IV) that it is necessary to measure also the change of the vector, for example by the parameter $\mathrm{d} B / \mathrm{d} t$. The experiments on magnetic field impact on the human body were performed at $50 \mathrm{~Hz}$ frequency. These impacts were not investigated at the frequencies between 1 and $50 \mathrm{~Hz}$. In 2014 the ICNIRP took as the reference the experiments on 3-7 T device for magnetic resonance imaging (MRI), which did not reflect the real processes in ordinary conditions. As the experimental result show, the main magnetic fields induced into the human body are below or above the $50 \mathrm{~Hz}$.
The processes emitting the magnetic field into the environment were investigated usually. The investigation of the influence of the environment onto the process, or humans, gives us the new possibilities of investigating the influence also of the movement in the Earth magnetic field. The movement of humans in the local magnetic field of the InTech devices can be compared with the movement in strong natural magnetic fields. The attention should be focused on the frequency range from $1 \mathrm{~Hz}$ to $10 \mathrm{~Hz}$, because the basic functions of human body are in this range. Present standards do not respond to the knowledge of medical experiments or WHO recommendations.

Human response to the energetic magnetic pulses is not investigated sufficiently because the human body is a complex biological organism. Based on the experimental results we can say that for further investigation the boundary conditions need to be specified as the step for the creation of the etalon for comparison, or the technical process as the etalon for other processes need to be specified. For the purpose of the personal safety the dosimetric measurements should be performed.

\section{Acknowledgments}

This work was supported by the APVV-15-0351, APVV-17-0184, APVV-18-0248, VEGA No. 1/0374/17, KEGA No. 052TUKE-4/2018, and KEGA No. 058TUKE-4/2018 projects.

\section{References}

[1] CENELEC, ENV 50166/1996, "Human Exposure to Electromagnetic Fields".

[2] "ICNIRP Guidelines for Limiting Exposure to Time Varying Electric, Magnetic and Electromagnetic Fields (up to $300 \mathrm{GHz}$ )" in: Health Phys. 74, 494 (1998).

[3] "ICNIRP Guidelines for Limiting Exposure to Time-Varying Electric and Magnetic Fields $(1 \mathrm{~Hz}-100 \mathrm{kHz})$ " in: Health Phys. 99, 818 (2010). 
[4] Directive 2013/35/EU, Electromagnetic Fields.

[5] Standard of building biology testing methods, SBM-2008, Institut für Baubiologie + Ökologie IBN.

[6] I. Belyaev, A. Dean, H. Eger et al., Rev. Environ. Health 31, 363 (2016).

[7] "Guidelines for Limiting Exposure to Electric Fields Induced by Movement of the Human Body in a Static Magnetic Field and by Time-Varying Magnetic Fields below $1 \mathrm{~Hz}$ ", in: Health Phys. 106, 418 (2014).
[8] M. Oravec, P. Lipovský, M. Šmelko, Low-Frequency Magnetic Fields in Work Space, 1st ed., SPBI, Ostrava 2018 (in Slovak).

[9] J. Hudák, J. Blažek, D. Praslička, I. Mikita, P. Lipovský, P. Gonda, J. Electr. Eng. 61, 28 (2010).

[10] H. Pačaiová, M. Oravec, M. Šmelko, P. Lipovský, F. Forrai, J. Electr. Eng. 69, 493 (2018).

[11] H. Pačaiová, J. Sinay, A. Nagyová, Measurement 100, 288 (2017). 